University of Nebraska - Lincoln

DigitalCommons@University of Nebraska - Lincoln

January 1991

\title{
On the Normalized Yield (Events/Rad/Dalton) of Biological Molecules Irradiated with Energetic Heavy Ions
}

Robert Katz

University of Nebraska-Lincoln, rkatz2@unl.edu

Part of the Physics Commons

Katz, Robert, "On the Normalized Yield (Events/Rad/Dalton) of Biological Molecules Irradiated with Energetic Heavy lons" (1991). Robert Katz Publications. 73.

https://digitalcommons.unl.edu/physicskatz/73

This Article is brought to you for free and open access by the Research Papers in Physics and Astronomy at DigitalCommons@University of Nebraska - Lincoln. It has been accepted for inclusion in Robert Katz Publications by an authorized administrator of DigitalCommons@University of Nebraska - Lincoln. 
Published in Radiation Physics and Chemistry 37:2 (1991), pp. 373-374;

formerly International Journal of Radiation Applications and Instrumentation. Part C. Radiation Physics and Chemistry

http://www.sciencedirect.com/science/journal/0969806X

Copyright (C) 1991 Pergamon Press plc. Used by permission.

Submitted February 20, 1990.

Short Communication

\title{
On the Normalized Yield (Events/Rad/Dalton) of Biological Molecules Irradiated with Energetic Heavy Ions
}

\author{
Robert Katz \\ University of Nebraska-Lincoln, Lincoln, NE 68588-0111, U.S.A.
}

When irradiated with electrons or $\gamma$-rays, a number of biological molecules display an approximately linear relationship between the reciprocal of the $D_{37}$ dose and molecular weight. This is conventionally plotted as a relation between target molecular weight and true molecular weight, where the target molecular weight $M_{t}$ is given as:

$$
M_{t} \times\left(D_{37}\right)=\alpha
$$

where $\alpha$ is approximately $10^{10} \mathrm{Da}-\mathrm{rad} / \mathrm{eV}$ of the energy assumed to be "deposited in the target" in a single "hit" for expression of the end-point. We emphasize that $D_{37}$ is expressed in rads for we will later write $d_{37}$ as having the same connotation but expressed in erg/g. The difference between the two is simply a factor of 100, but the use of two different symbols makes for a smoother presentation. As a reminder, the $D_{37}$ dose is the dose, in rads, at which there is $37 \%$ survival of the target molecules irradiated by $\gamma$-rays. Different authors (Hutchinson and Pollard, 1961; Dertinger and Jung, 1970; Alper, 1979) estimate the required energy deposition to be about 60 or 75 $\mathrm{eV}$. See the references for the details of the calculations and for plotted relationships between the target molecular weight and the true molecular weight.

We will show that within the accuracy with which equation (1) yields agreement between the target molecular weight and the true molecular weight, the normalized response of these molecules to track segment irradiation with energetic heavy ions is proportional to the RBE. By normalized response we mean response per Da rather than response per target molecule, normalizing for differences in molecular weight of the irradiated molecules.

Since the RBE for 1-hit detectors depends strongly on the $D_{37}$ dose, and thus on the molecular weight, the "normalized yield" does not result in a single valued function which relates events/rad/Da to LET (Chatterjee, 1989).
For the heavy ion irradiation of 1 hit detectors we know (Butts and Katz, 1967) that

$$
\mathrm{RBE}=\sigma\left(d_{37}\right) \rho / \mathrm{L}
$$

when all quantities on the right are expressed in cgs units, that is $\sigma$ is in $\mathrm{cm}^{2}, d_{37}$ is in $\mathrm{erg} / \mathrm{g}, \rho$ is in $\mathrm{g} / \mathrm{cm}^{3}$, and LET $(L)$ is in erg/cm. A plot of RBE vs LET for different values of the $d_{37}$ dose is displayed there also.

The normalized yield may be written as a product of factors as:

$$
\text { events/Da-rad } \begin{aligned}
& =(\text { events } / \mathrm{cm}) \times(\mathrm{cm} / \mathrm{erg}) \\
\times & \left(\mathrm{cm}^{3} / \mathrm{Da}\right) \times\left(\mathrm{g} / \mathrm{cm}^{3}\right) \times(\mathrm{erg} / \mathrm{g}-\mathrm{rad}) .
\end{aligned}
$$

If the interaction cross section is $\sigma$, the number of target molecules $/ \mathrm{cm}^{3}$ is $N$, the true molecular weight is $M$, we write

$$
\begin{aligned}
& \text { the number of events } / \mathrm{cm}=\sigma N \\
& \text { the number of } \mathrm{Da} / \mathrm{cm}^{3}=N \times M
\end{aligned}
$$

we have

$$
\text { events } / \text { Da-rad }=(\sigma N) \times(1 / L) \times(1 / N M) \times \rho \times 100 .
$$

If we make the approximation that the target molecular weight is equal to the true molecular weight and combine equations (1), (2) and (4) we find

$$
\text { events } / \text { Da-rad }=R B E / \alpha \text {. }
$$

The relationship of equation (5) is applicable only to 1-hit detectors for which the target molecular weight approximates the true molecular weight, as for dry enzymes and viruses. It may be applicable to single strand breaks in DNA, for direct effects. It may also be applicable to both single and double strand breaks in SV-40 DNA in $E_{0}$ buffer, for these act as 1-hit detectors, though 
the action is through the indirect effect and the value of $\alpha$ may depart from that suggested above. It is not applicable to 2-hit detectors, such as double strand breaks in DNA resulting from the direct effect.

\section{Acknowledgment}

Supported by the U.S. Department of Energy.

\section{References}

Alper, T. (1979) Cellular Radiobiology. Cambridge University Press, Cambridge.
Butts, J. J., and Katz, R. (1967) Theory of RBE for heavy ion bombardment of dry enzymes and viruses. Radial. Res. 30, 855.

Chatterjee, A. (1989) Radiobiological effects of high LET particles: DNA strand breaks. Nucl. Instr. Meth. Phys. Res. A280, 439.

Dertinger, H. and Jung, H. (1970) Molecular Radiation Biology. Springer, Berlin.

Hutchinson, F., and Pollard, E. (1961) Physical principles of radiation action. In Mechanisms of Radiobiology (Edited by Errara, M., and Forssberg, A.), p. 71. Academic Press, New York. 